\title{
Congenital corneal staphyloma: clinical, radiological, and pathological correlation
}

\author{
STEVEN R LEFF,' JERRY A SHIELDS,' JAMES J AUGSBURGER,' \\ ANTHONY D SAKOWSKI Jr, ${ }^{2}$ AND CHARLES J BLAIR \\ From the 'Oncology Service and Pathology Department, Wills Eye Hospital, Jefferson Medical College, \\ Thomas Jefferson University, Philadelphia, and from the ${ }^{2}$ Department of Ophthalmology, the Medical College \\ of Virginia, Richmond, Virginia, USA.
}

SUMMARY A 2-year-old child was referred because of a prominent blind left eye with an opaque cornea. Although extraocular extension of a retinoblastoma was an initial diagnostic possibility, computed tomography (CT) showed only a large globe with a corneal staphyloma. Because of the cosmetically unacceptable appearance the involved eye was enucleated. The clinical, CT, and histopathological features of congenital corneal staphyloma are discussed, as well as the possible pathogenic mechanisms.

Congenital corneal staphyloma is a rare condition. It is presumed to be a developmental abnormality, characterised by an opacified, ectatic cornea that protrudes forward between the eyelids. ${ }^{2}$ The anterior segment of the involved eye is usually markedly abnormal. The condition can be either unilateral or bilateral. We report here the case of a child with a severe unilateral form of corneal staphyloma and review the clinical, radiological, and pathological features of this condition.

\section{Case report}

A 26-month-old Guatemalan girl was examined at the Oncology Service at Wills Eye Hospital in March 1984 . She was a native Mayan Indian villager specifically brought to the United States for treatment of her eye condition. The past ocular and medical history was therefore incomplete. Apparently she was the product of a normal, full-term pregnancy except that the mother had an intestinal illness during the eighth month. The child was born at home with only a midwife present. At 5 days of age both eyes had a bloody, purulent discharge, which was successfully treated with topical antibiotics. At 2 months of age an opaque film was noted on the left cornea. She was seen for the first time by a physician at age 26 months. The child was sent to the United States and subsequently to the Oncology Service for treatment of possible advanced retinoblastoma.

Correspondence to Steven R Leff, MD, Oncology Service, Wills Eyc Hospital, Ninth and Walnut Strects, Philadelphia, PA 19107.
On examination the child had normal fixation and following movements of the right eye but no vision in the left. The right eye was completely normal. Examination of the left eye revealed a protruberant corneal cone bulging $10 \mathrm{~mm}$ forward from the normal limbal plane and extending anteriorly through the lid fissure. The corneal surface was yellow-white and appeared keratinised. The corneal diameter appeared much larger than normal. The conjunctiva was clear. No structures could be seen posterior to the cornea.

Ultrasonography revealed a large eye, $27 \mathrm{~mm}$ in anteroposterior length, with an abnormal anterior segment but apparently normal retina and vitreous.

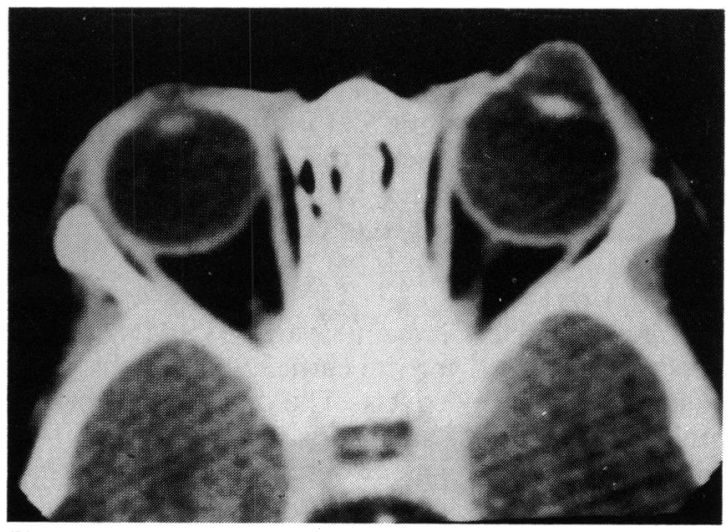

Fig. 1 Orbital CT scan showing ectatic, protruding cornea and enlarged anterior segment. Lens and posterior segment appear normal and without calcification. 


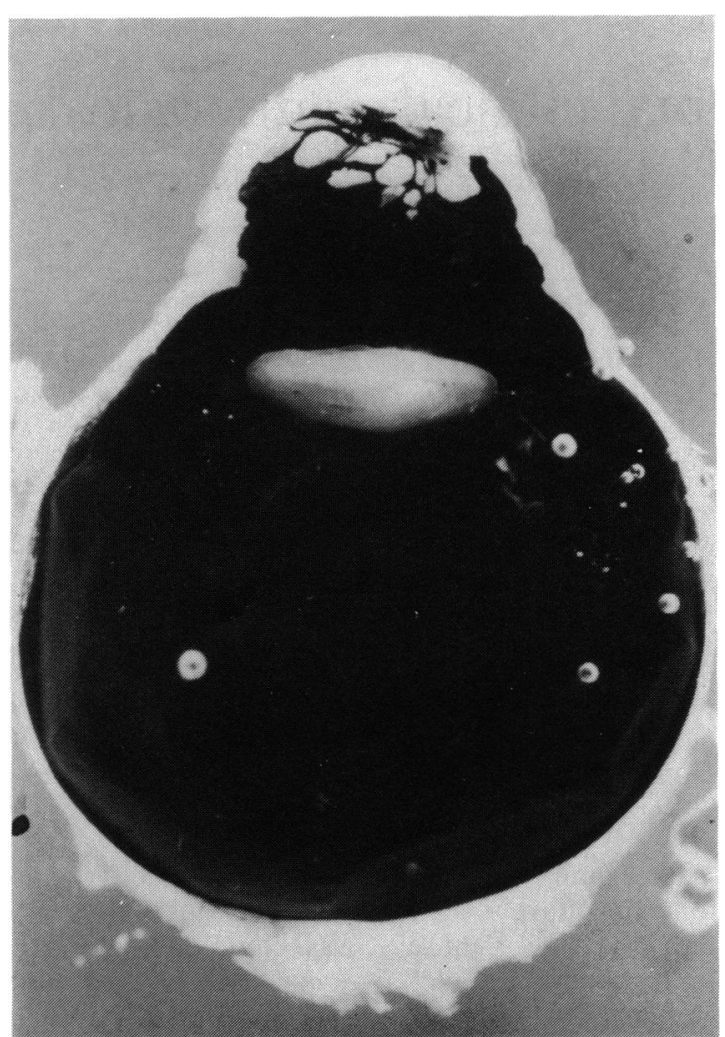

Fig. 2 Gross sectioned globe demonstrating iris tissue adherent to posterior cornea.

Computerised tomography (CT) showed an outpouching of the globe's anterior aspect (Fig. 1). There was no contrast-enhancing abnormality or evidence of fatty tissue density in the anterior segment. There was no intraocular calcification. The right eye and both orbits were normal.

The diagnosis based on the above findings was congenital corneal staphyloma. Because of the lack of vision, the chances of pain from secondary glaucoma, and the cosmetic deformity in a unilateral presentation, it was elected to enucleate the left eye. After uneventful surgery and the fitting of a prosthesis the patient returned to Guatemala.

\section{PATHOLOGY}

The enucleated left globe measured $31 \times 24 \times 24 \mathrm{~mm}$. The horizontal and vertical corneal dimensions were 16 and $14 \mathrm{~mm}$ respectively. The opaque-tan cornea projected forward as a cone for $12 \mathrm{~mm}$ (Fig. 2). The lens and posterior segment were normal, except that the optic nerve was severely cupped.

Microscopic examination of the left eye showed central corneal ectasia. The peripheral cornea was thickened with irregular epithelium due to rete pegs,

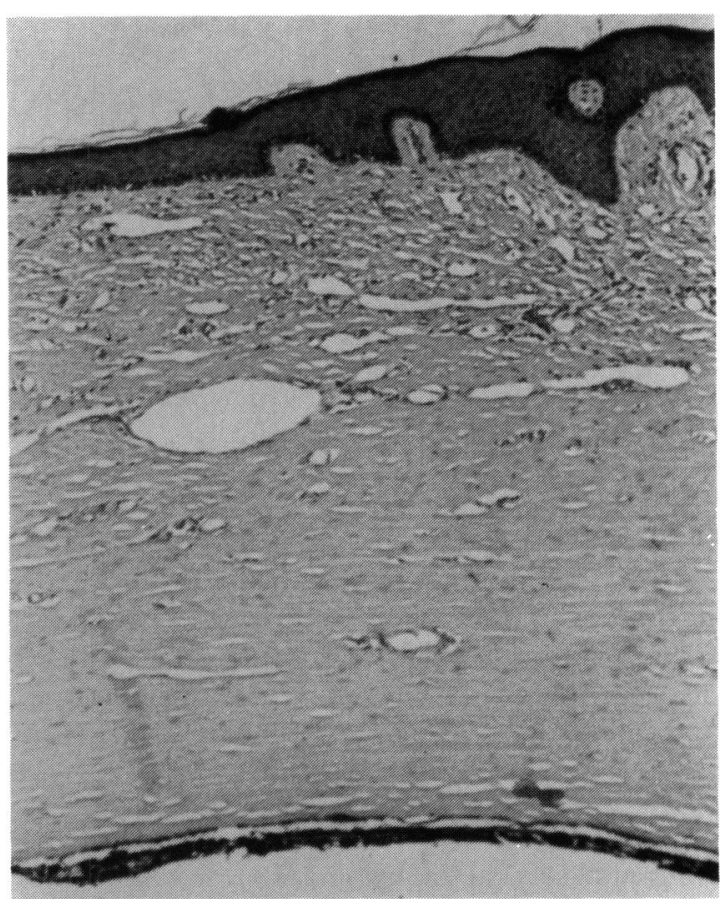

Fig. 3 Examination of the peripheral cornea. Note the rete pegs, vascularised stroma, and adherence of the atrophic iris resulting in total anterior synechiae. (Haematoxylin-eosin, $\times 15$ ).

projections of the epithelium into the vascularised superficial stroma (Fig. 3). The central cornea showed keratinisation. Bowman's membrane was thin and atrophic, and there was a mild lymphocytic infiltration surrounding blood vessels which were in the stroma (Fig. 4). Descemet's membrane and the endothelium were completely absent (Fig. 5). The posterior aspect of the cornea was entirely lined with atrophic iris tissue which obliterated the anterior chamber (Fig. 6). The lens and vitreous were normal. The retina showed thinning of the ganglion cell and nerve fibre layers. There were a few lymphocytes round the retinal blood vessels. The optic nerve was severely cupped, with retrodisplacement of the lamina cribrosa. A mild proliferation of astrocytes was present in the substance of the nerve.

The final pathological diagnosis was congenital corneal staphyloma, corneal vascularisation and keratinisation, absence of Descemet's membrane, total anterior synechiae, angle-closure glaucoma, and cupping of the optic disc.

\section{Discussion}

Congenital corneal staphyloma typically presents in the young child as an opaque, ectatic corneal pro- 


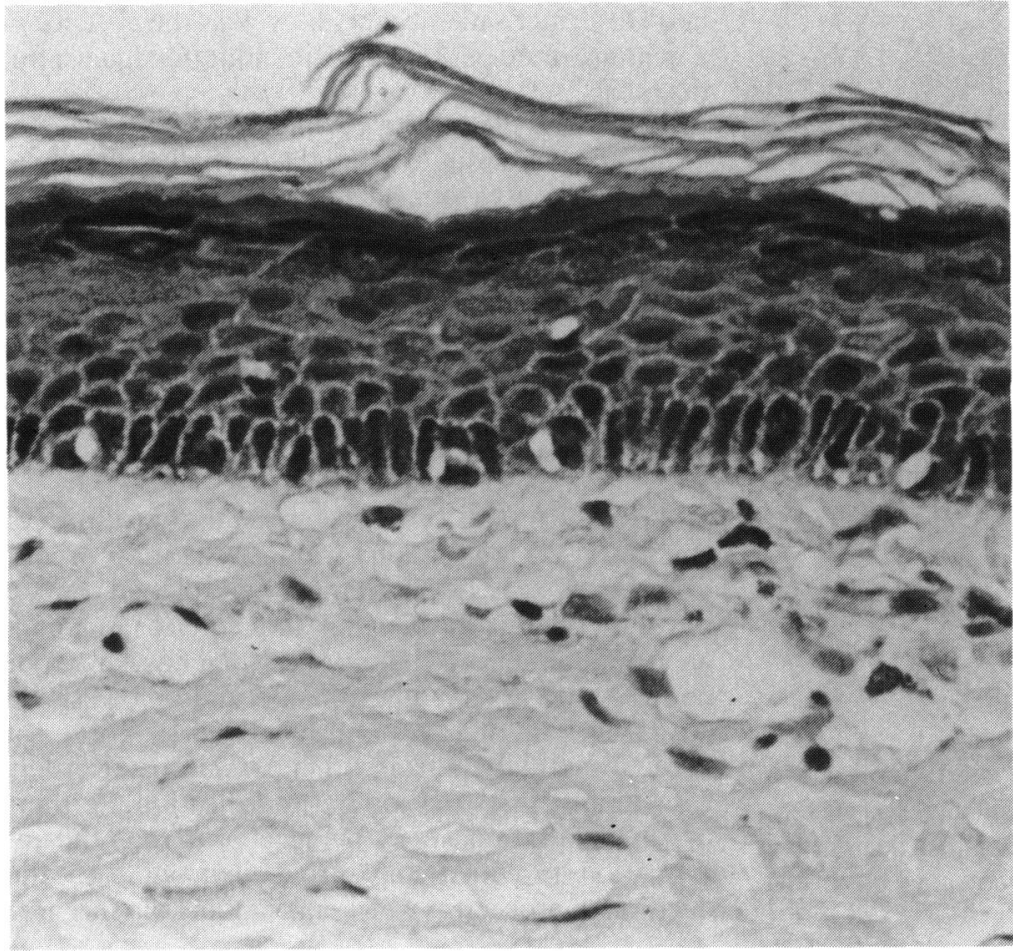

Fig. 4 The central anterior cornea shows keratinisation, abnormal epithelium, and lack of Bowman's membrane. (Haematoxylin-eosin, $\times 60)$.

trusion lined on its inner surface by atrophic iris. ${ }^{134}$ Secondary angle closure resulting from total anterior synechiae leads to elevation of the intraocular pres- sure and optic disc cupping. Protrusion of the bulging cornea between the eyelids can result in exposure keratitis, epithelial metaplasia, and keratinisation.

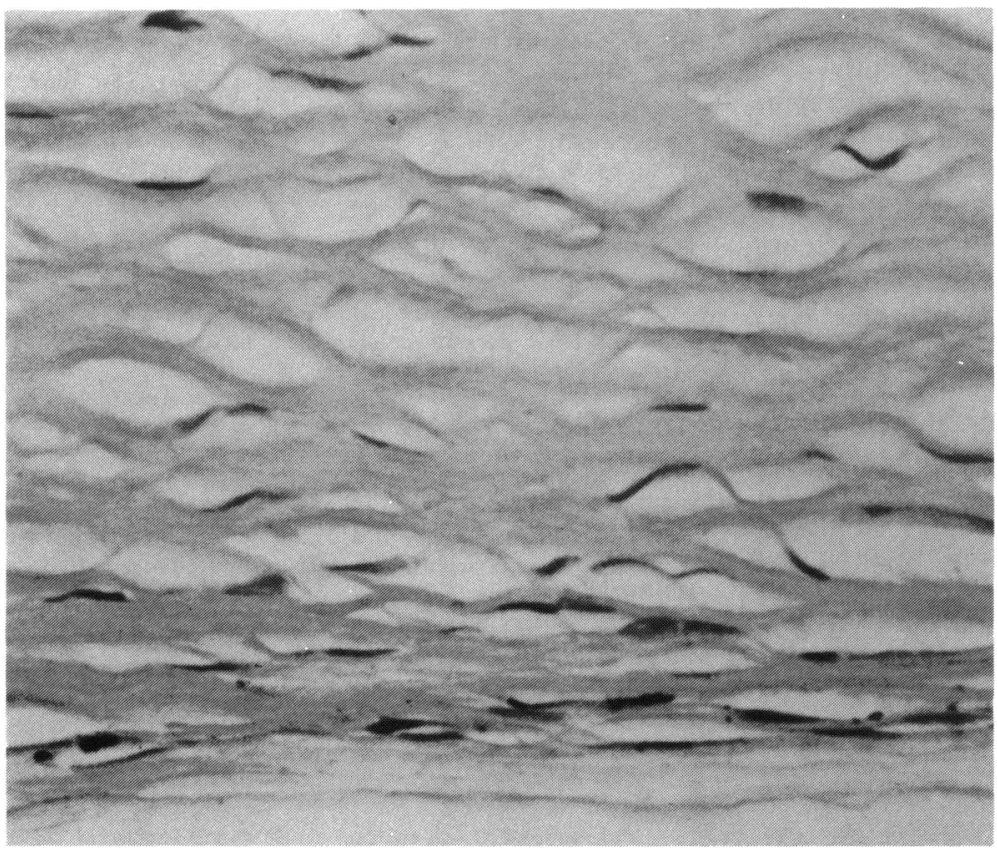

Fig. 5 Examination of the central posterior cornea through the pupil. Note the complete lack of Descemet's membrane and the endothelium. (Haematoxylineosin, $\times 60$ ). 


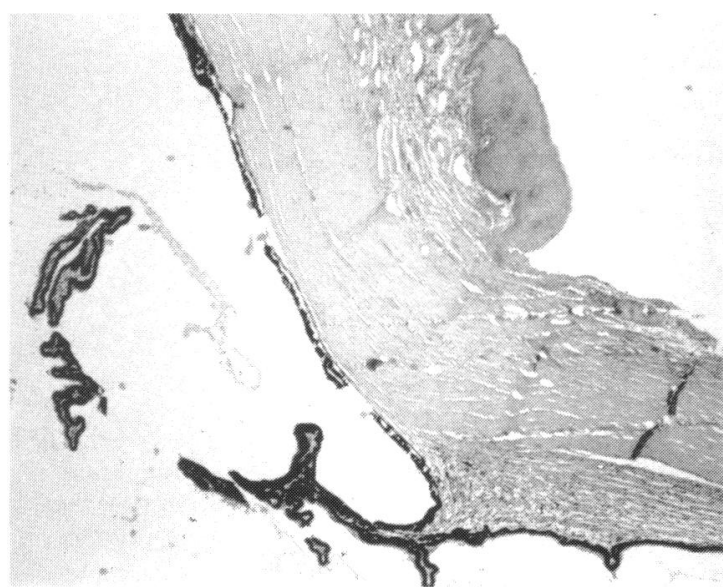

Fig. 6 The angle shows total peripheral anterior synechiae obliterating the anterior chamber. The ciliary body is markedly atrophic. (Haematoxylin-eosin, $\times 5)$.

Keloid formation has been reported to occur in staphylomatous cornea, presumably as a response to chronic corneal inflammation. ${ }^{5}$ Dermis-like choriostomas arising from the ectatic corneas have also been reported. ${ }^{6}$

Histopathological and electron microscopic study of eyes with congenital corneal staphylomas characteristically shows absence of Descemet's membrane and corneal endothelium. ${ }^{2}$ Inflammatory cells are notably absent in the stroma of the staphylomatous cornea in many cases. The absence of corneal endothelial cells combined with the lack of stromal inflammatory changes suggests that congenital corneal staphyloma is developmental rather than inflammatory in origin. ${ }^{2}$ Congenital corneal staphyloma, like Peters' anomaly, is now presumed to be due to failure of the normal migration of neural crest cells. According to this view it is simply a more extreme form in the spectrum of central anterior segment mesenchymal dysgenesis than is Peters' anomaly. ${ }^{27}$ The combination of congenital corneal staphyloma with the median cleft face syndrome supports this view and puts the abnormal differentiation at the 17 to $20 \mathrm{~mm}$ stage of development (approximately seven weeks' gestation). ${ }^{x}$

Our patient fits both the clinical and histological definition of congenital corneal staphyloma. Nevertheless, in view of the child's vague postnatal history, the sequelae of a perforated corneal ulcer could also be considered as a possible explanation for this presentation. However, the total lack of endothelium and Descemet's membrane, as well as the absence of a demonstrated perforation site, militates against this diagnosis.

In view of the severe cosmetic deformity of this blind, glaucomatous eye and the normal condition of the fellow eye we considered enucleation to be the most appropriate treatment. Although most eyes with congenital corneal staphyloma have come to enucleation, some success in treating the milder forms of this disorder with penetrating keratoplasty has recently been reported. ${ }^{2}$ All bilateral cases of congenital corneal staphyloma probably warrant a surgical attempt to salvage some vision in at least one eye.

We believe this paper reports the first use of computerised tomography in the evaluation of corneal staphyloma. It was far more helpful than contact ultrasonography in showing the anterior segment abnormality and excluding other diagnoses such as dermoid cyst or retínoblastoma. It should be especially useful in differentiating the milder forms of corneal staphyloma from other associated disorders with buphthalmos and corneal opacification. Furthermore, if keratoplasty is being considered, the information provided may prove invaluable in the decision to proceed as well as in planning the surgery.

This work was supported in part by the Pennsylvania Lions Sight Conservation and Eyc Research Foundation, Inc., and the Ocular Oncology Fund, Wills Eye Hospital.

\section{References}

1 Duke-Elder S. Normal and abnormal development. Congenital deformities. System of ophthalmology. St Louis: Mosby, 1964: 3 (2): 523-7.

2 Schanzlin DJ, Robin JB, Erickson G, Lingua R, Minckler D, Pickford M. Histopathologic and ultrastructural analysis of congenital corncal staphyloma. Am J Ophthalmol 1983; 95: 506-14.

3 Olson JA. Congenital anterior staphyloma. Report of two cases. $J$ Pediatr Ophthalmol 1971; 8: 177.

4 Weizenblatt S. Congenital malformations of cornca associated with embryonic arrest of ectodermal and mesodermal structures. Arch Ophthalmol 1954; 52: 415-25.

5 Smith HC. Keloid tumors of the cornea. Trans Am Ophthalmol Soc 1940; 38: 519-38.

6 Bernuy A, Contreras F, Maumenec AE, O'Donnell FE Jr. Bilateral, congenital, dermis-like choristomas overlying corneal staphylomas. Arch Ophthalmol 1981; 99: 1995-7.

7 Waring GO III, Rodrigues MM, Laibson PR. Anterior clcavage syndrome. A step-ladder classification. Surv Ophthalmol 1975; 20: 3-27.

8 Kensey JA, Strecten BW. Ocular abnormalitics in the median cleft face syndrome. Am J Ophthalmol 1977; 83: 261-6.

Accepted for publication 24 October 1985. 